\title{
Fishery Logistics Insurance Management Schemes
}

\author{
Yan-Ling Wang ${ }^{1,2}$ \\ ${ }^{1}$ Zhejiang Wanli University, 315100 Ningbo, Zhejiang, P. R. China \\ ${ }^{2}$ Dalian Maritime University, 116026 Dalian, Liaoning, P. R. China \\ E-mail: yanling_wang1@yahoo.com.cn
}

Keywords: Fishery supply chain; insurance; risk diversity; insurance contract.

\begin{abstract}
The intense competition of global markets and consumers' high expectations forced enterprises to invest and concentrate on the relationship with their customers and suppliers. The growing interest in supply chain management, both in developed and developing countries in the fisheries. With the catastrophic events in the fisheries supply chain, the diversity of the fisheries risk and insurance issues become increasingly important. However, participants in the supply chain is a separate and independent economic entities, and only consider their own interests. In this article, the fisheries supply chain insurance contract on the basis of the model and the diversity of the fisheries risk and insurance policy issues, the behavior of each participant. In this article, the diversity of the fisheries supply chain risk and insurance process, the lack of sufficient knowledge of the fisheries supply chain contract signing or the exact probability of the insured event, the fisheries supply chain risk insurance companies use the information provided by the fisheries supply chain contract signature the signing of the contract or the behavior of the fisheries supply chain insurers of people insured or fisheries supply chain and fisheries supply chain in order to establish the parameters of the insurance contract of the fisheries supply chain.
\end{abstract}

\section{Introduction}

The intense competition of global markets and consumers' high expectations forced enterprises to invest and concentrate on the relationship with their customers and suppliers. Promote the development of information and communication technologies, frequently exchange large amounts of information between the chain participants, the purpose of coordination, increased interest in supply chain management. Therefore, it is necessary and a joint approach, to establish more effective and efficient supply chain business partners the opportunity. National retail system changes the competitiveness of enterprises of the national retail industry, both small and large-scale innovation and lower costs, more responsive to consumer demand. This is the reason and supply chain management can help the retail system in the country. Simply ignore a national retail supply chain to increase future losses or business interruption potential and possibilities. Recently, interest in supply chain management to enhance fisheries, both in developed and developing countries. Executives, as their counterparts in the manufacturing and retail trade, fishing enterprises are increasingly aware that successful coordination, integration, and key business processes to manage the entire supply chain members will ultimately determine the success of their competition. In addition, the fishing enterprises are increasingly aware that they no longer compete fully self-governing entity. On the contrary, the competition between the entire supply chain appears. Has also been driven by increased interest in supply chain management, frequently exchange large amounts of information between the chain participants, the purpose of coordination, information and communication technology development. Therefore, it is necessary and direction of a joint approach to the establishment of more effective and efficient fisheries supply chain [1] business partners the opportunity. This is especially the fisheries supply chain, because the shelf life of fishery products and restrictions on the increasing concerns of consumers, safety and environment-friendly fisheries production methods. From developing countries, as well as to provide market access for local, regional and export markets, producers, fisheries chains and networks play an important role. System in the fisheries, the fisheries 
industry competitiveness of enterprises, small and large there will be innovation and lower costs, more responsive to the changing needs of consumers. This is supply chain management can help the fishery system. However, due to the existence of an unprecedented scale catastrophic events, such as collision, pollution, caused by the hurricane losses (claims), the various risks inherent in fisheries supply chain, especially those involved in fisheries supply chain. Simply ignore the risk of the fisheries supply chain base, the only increase in future losses or business interruption potential and possibilities. With the catastrophic events in the fisheries supply chain, the dispersion of risk and insurance issues become increasingly important. The diversity of the fisheries supply chain risk and insurance process, lack of adequate knowledge, the exact probability of the fisheries supply chain contract signature or insurance accident, the fisheries supply chain risk insurance, usually with the signing of the contract or insurance by the fisheries supply chain The information provided by the fisheries supply chain contract signatory, or an insurer to establish the behavior of the parameters of the fisheries supply chain insurance contract execution. In this article, we will take into account the diversity of the fisheries supply chain risk and insurance issues, especially the diversity of the fisheries supply chain risk and insurance issues in the supply chain risk insurance cases. The diversity of the fisheries supply chain risks that may occur between the different insurance companies of the fisheries supply chain and insurance, so that one or two to avoid destruction. Diversity in the fisheries supply chain risk and the insurance industry, the insurance institutions of the fisheries supply chain, customers avoid the risk of transfer of risks and profits, and the second fishery supply chain insurance carrier (the fisheries supply chain insurance institutions), fisheries supply chain insurance companies. In recent years, the diversity of the fisheries supply chain risk and insurance markets, especially in the fisheries supply chain in the form of funds, have experienced rapid development. Rothschild and Stiglitz in the literature [3], the availability of the insurance contract through the competitive market. With perfect competition between insurance companies, they found that the customers' risk aversion, there is no contract of insurance. However, the diversity of the fisheries supply chain risk and insurance markets, in particular, is a very large fishing supply chain insurance contract, it is more appropriate in the context of the non-competitive, as the process of direct negotiations, the negotiation of fisheries for should chain insurance contract between insurance companies and fisheries of the fisheries supply chain supply chain customers. [4], Kihlstrom and Roth non-competitive market research, insurance companies in the risk-neutral and risk-averse insurance contract to bargain the terms of the contract of personal insurance. They showed a higher expected profits of the cooperative Nash setting the insurance company negotiations, more risk-averse individuals and negotiations. Ross extended to avoid the risk of negotiating non-cooperative model of analysis and discussion. Again, it shows that the risk neutral agent's expected profit is higher, the more risk-averse individual negotiations. In the fisheries supply chain insurance, the insurance company of the fisheries supply chain play and risk-averse customers, the fisheries supply chain insurance bargaining game. When the production / business policy in the fisheries supply chain between the insurance companies have different expected risk and potential profit, risk, it needs to affect the potential profit, it can receive a variety of options. The diversity of the fisheries supply chain risks in the fisheries supply chain insurance, including the diversity of the fisheries supply chain risk and insurance, a variety of formal models, often ignoring the activities of the fisheries supply chain insurers. Lack of sufficient knowledge about the fisheries supply chain insurance accident probability in the diversity of the non-competitive fisheries supply chain risk and insurance, commonly used in the diversity of the fisheries supply chain risk and insurance companies by the signing of the fisheries supply chain insurance contract or fisheries information supply chain policyholders, this is a distortion of information. In this article, we will take into account the diversity of diversity and fisheries in the fisheries supply chain risk supply chain risk and insurance companies, insurance, fisheries supply chain contract signatory or the fisheries supply chain insurers to disclose information model of the fisheries supply chain parameters of the insurance contract. On the one hand, all the fisheries supply chain contract signing or the fisheries supply chain insurer's risk is neutral. On the other hand, the manipulation of information is a major phenomenon, because all of the fisheries supply chain contract 
signed or fisheries supply chain insurance in their attitude towards risk is the same, it is admissible to any re-allocation to provide all of the fisheries supply chain contract signing or the fisheries supply chain insurers have adequate information to each other, if the distribution of the information is incomplete, that is asymmetrical, then you can violate the requirement of balanced premiums and expected expenditures. Negotiations of the game can provide a consistent and rigorous economic reasons, the bargaining advantage of the diversity of the fisheries supply chain risk and insurance issues, the diversity of these fisheries supply chain risk and insurance case to establish a new method [5].

\section{Problem Representation}

Diversity in the fisheries supply chain risks and the insurance industry, the diversity of the fisheries supply chain risk and insurance companies play a risk-averse customers, the fisheries supply chain insurance contracts signed or the fisheries supply chain insurance bargaining game. The probability of the insured event, the fisheries supply chain, lack of adequate knowledge, the diversity of the fisheries supply chain risk and insurance companies typically use the information provided by the signing of the fisheries supply chain insurance contract or the fisheries supply chain insurance, the establishment of the fisheries supply chain parameters of the insurance contract. Therefore, held in the diversity of the fisheries supply chain risk and insurance companies or the signing of the contract by the fisheries supply chain insurance or the risk of the fisheries supply chain insurance, asymmetric information. Bargaining game can be used to establish the diversity of the fisheries supply chain risk and insurance law the diversity of the fisheries supply chain risk and insurance cases. Through the signing of the diversity of co-operation, fisheries supply chain risk and insurance contracts of insurance companies and the fisheries supply chain or fisheries supply chain, the insurer may re-allocate their risk, therefore, improve their welfare. In this section, we consider the fisheries supply chain insurance contract the insured's signature or the fisheries supply chain diversity of trade union fisheries supply chain risk and insurance. The objective function of any of the fisheries supply chain insurance activities, including the diversity of the fisheries supply chain risk and insurance activities, can be expected that the cause is defined as [5]

$$
E\left\{U_{i}\right\}=g_{i}-r_{i}+p_{i}\left[h_{i}-Q_{i}\right]_{, i \in I}
$$

where ${ }^{g_{i}}$ represents the income provided by the economic activity of the $i$ th fishery supply chain insurance contract signatory or fishery supply chain insurant including its input into this activity and preventive actions, ${ }^{r}$ is the fishery supply chain insurance premium, ${ }^{h}$ is the fishery supply chain insurance money, $p_{i}$ is the probability of fishery supply chain insured accident, $Q_{i}$ is the loss inflicted by the fishery supply chain insured accident; and $I \in\{1,2, \cdots, N\}$ is the set of fishery supply chain insurance contract signatory or fishery supply chain insurants. For simplicity, in this paper, we assume that in a time interval, the collection of premiums and payment of compensation time, the remaining funds to scrap funding for future time intervals. Assumptions, the fisheries supply chain for all insurance contracts signed or the fisheries supply chain insurance risk is the same, but different fisheries supply chain insurance accident and the possibility of loss. Re-allocation of risk, different risk attitudes of the fisheries supply chain agents. That, on the one hand, all the insured risk is neutral, on the other hand, the main phenomenon in the diversity of the fisheries supply chain risk and insurance research is the manipulation of information. Any redistribution of the fisheries supply chain insurance contract signatory or the fisheries supply chain insurance in their attitude towards risk is the same, it is admissible, the fisheries supply chain for all insurance contracts signed or fisheries supply chain is insurance requirements, each complete information. If the distribution of the information is not complete, that is, asymmetry, fisheries supply chain balanced premiums and expected fisheries supply chain insurance payment requirements can be violated. 
Under full information distribution, the total fishery supply chain insurance premium is

$$
R=\sum_{i \in I} r_{i}
$$

and the expected fishery supply chain insurance money is

$$
H=\sum_{i \in I} p_{i} h_{i}
$$

If unprofitable fishery supply chain risk diversity and insurance is considered, by the principle of equivalence, there must be

$$
R=H
$$

that is,

$$
\sum_{i \in I} r_{i}=\sum_{i \in I} p_{i} h_{i}
$$

In the case of fishery supply chain insured accident, there must be

$$
\begin{gathered}
h_{i}=Q_{i}, \quad i \in I \\
H=\sum_{i \in I} p_{i} Q_{i}
\end{gathered}
$$

If the damages are refunded completely, then under the conditions of full information distribution, the following mechanism of fishery supply chain risk diversity and insurance can be used

$$
r_{i}=p_{i} Q_{i}, i \in I
$$

Within this framework, the signatory of the insurance contract of the fisheries supply chain supply chain for each fishery or fisheries supply chain insurance premiums, it is precisely equal to its expected losses. However, if each of the fisheries supply chain insurance contract signing or the fisheries supply chain insured only, not the rest of the fisheries supply chain insurance contract signing or fisheries supply chain insure observation of a individual parameters, then the mechanism (8) can not be to use. Let us assume that the losses $\left\{Q_{i}\right\}$ incurred by the fishery supply chain insured accidents are observable and their probabilities $\left\{p_{i}\right\}$ are non-observable, but their estimates $\left\{s_{i}\right\}$ can be revealed by the fishery supply chain insurance contract signatory or fishery supply chain insurants to each other. Then, under normal circumstances, all the fisheries supply chain insurance contract signing or the fisheries supply chain insured insisted on reducing the probability of the fisheries supply chain insurance accident. Therefore, the minimum estimated revelation will be a balance. Therefore, we should use some of the diversity of alternative risk and insurance mechanisms to express the diversity of the fisheries supply chain risk and insurance. The diversity of the fisheries supply chain risk and insurance, however, this balance is not possible. The insured from the insurance contracts signed or fishing in the fisheries supply chain supply chain point of view, the diversity of the fisheries supply chain risk and insurance by virtue of its non-commercial direction (when the commercial orientation is that the similar approach.), the one zero sum game, it are as follows that the conditions (5), with a total fisheries supply chain insurance premium must is the damage of equality the total amount of compensation.

\section{Summary}

Participants in the supply chain is a separate and independent economic entities, and only consider their own interests. In this article, the fisheries of the fisheries supply chain insurance contract risks and insurance policy issues, on the basis of each participant's behavior patterns and diversity. In this article, the fisheries supply chain risk and insurance process, the lack of sufficient knowledge of the fisheries supply chain diversity of signed contract or an insurance accident, the exact probability of the fisheries supply chain risk insurance companies use the information provided in fisheries supply chain contract the behavior of the signing of the contract signed or fisheries supply chain insurance companies in the insurance contract by the insurer or the fisheries supply chain and fisheries supply chain in order to establish the fisheries supply chain parameters. 


\section{Acknowledgments}

This work was supported in part by the National Soft Science Foundation of China (No. 2010GXS5D214), the Education of Ministry Humanities Social Sciences Research Project (No. 11YJA630135), the Science Foundation of Zhejiang Wanli University.

\section{References}

[1] M. G. Sylvia Thompson, M. T. Morrissey, "Seafood Traceability in the United States: Current Trends, System Design, and Potential Applications", Comprehensive Reviews in Food Science and Food Safety, pp. 1-7, vol. 4, no. 1, 2005.

[2] P. Bennett, "Mutual risk: P\&I insurance clubs and maritime safety and environmental performance", Marine Policy, pp. 13-21, vol. 25, no. 1, 2001.

[3] M. Rothschild and J. E. Stiglitz, "Equilibrium in competitive insurance markets: an essay on the economics of imperfect information”, Q. J. Econ., pp. 629-649, vol. 90, no. 3, 1976.

[4] R. E. Kihlstrom and A. E. Roth. "Risk aversion and the negotiation of insurance contracts", J. Risk Insurance, vol. 49, no. 2, pp. 372-387, 1982.

[5] A. Alexandre, Handbook of Asset and Liability Management: From Models to Optimal Return Strategies, Wiley, 2008. 